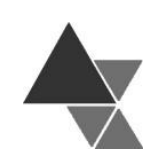

\title{
Segurança dos alimentos nas Instituições Beneficentes
}

\author{
Fabiana de Aro', Thamara Magaly Barboza², Ariadine Pires², Drielly R. Viudes², Fabiana \\ M. O. Hernandez ${ }^{2}$ e Daniela Navarro D'Almeida Bernardo²
}

A saúde da população brasileira tem sido afetada pelo processo de transição nutricional, com tendências de declínio da desnutrição e aumento considerável do número de pessoas com excesso de peso e doenças provenientes desse quadro, devido a hábitos alimentares inadequados. A análise descritiva foi realizada em seis instituições atendidas pelo Programa de Aquisição de Alimentos - PAA na cidade de Araçatuba - SP, com o objetivo de avaliar a influência das ações educativas para a segurança alimentar nas cozinhas e a diminuição do desperdício de alimentos por meio do aproveitamento integral e conservação. As ações educativas para proporcionar alterações no comportamento dos funcionários devem acontecer de forma contínua e sistemática, além de integrar as ações de Segurança Alimentar e Nutricional voltada às questões sanitárias deve se enfatizar a sua complexidade e a sua importância para promoção da saúde das pessoas atendidas por essas Instituições. O envolvimento dos funcionários requer motivação intrínseca, contudo o acompanhamento do nutricionista estimulando conhecimentos e práticas valorizam a equipe e influenciam o comportamento e motivam para a adesão de novos conceitos que irão impactar na qualidade e produtividade.

Palavras-chave: desnutrição, prevenção de doenças, saúde pública, segurança alimentar.

\section{Food Security in Charities}

The health of Brazilian population has been affected by the nutritional transition process, with tendencies of malnutrition decline and a considerable increase in the number of people with overweight and diseases coming framework due to inappropriate eating habits. The descriptive analysis it was realized in six institutions attended for Acquisition Program of Food - APF in Araçatuba city, with the objective to evaluate the influence of educative actions for the food security in the kitchens and the wastage decrease of food through a whole utilization and conservation. The educational actions to supply behavior alterations of employees must happen in a continuous and systematic way, besides integrating the Food Security actions and Nutritional focused in the health issues must be emphasize its complexity and importance for the health promotion of people who are attended by these institutions. The involvement of employees requires intrinsic motivation, however the accompaniment of a Nutritionist stimulating knowledge and practices the value the team and influence on the behavior and adherence of new concepts that will impact in the quality of productivity.

Keywords: malnutrition, disease prevention, public health, food safety.

${ }^{1}$ Centro Universitário Salesiano Auxilium de Araçatuba -SP. Endereço para correspondência: Rua Presidente Bernardes no 482, apto. 113, Bairro Vila Santo Antônio. CEP: 16015-353. Araçatuba, SP.E-mail: fabiana.aro@gmail.com

${ }^{2}$ Centro Universitário Salesiano Auxilium de Araçatuba - SP. 


\section{INTRODUÇÃO}

Os danos para a saúde dos seres humanos que podem decorrer do consumo insuficiente ou excessivo de alimentos são conhecidos há muito tempo, mas recentemente surgiram evidências de que características qualitativas da dieta são importantes, principalmente, no que diz respeito às doenças crônicas degenerativas da idade adulta[1].

Entender os problemas de alimentação e nutrição, nas suas dimensões biológica e social, possibilita analisar alternativas de intervenções que visem mudanças alimentares apoiadas nas dimensões sensoriais, cognitivas, simbólicas e práticas alimentares, além dos efeitos da transição nutricional, que reforçam a evolução dos padrões de consumo alimentar no Brasil, marcado pelo declínio no consumo de alimentos básicos e tradicionais e aumento no consumo de alimentos industrializados[2].

Hábitos e práticas alimentares são construídos com base em determinações socioculturais. No mundo contemporâneo, a mídia desempenha um papel estruturador na construção e desconstrução de procedimentos alimentares ${ }^{[3]}$.

$\mathrm{Na}$ dimensão biológica, a alimentação humana como um ato social e cultural faz com que sejam produzidos diversos sistemas alimentares que intervêm nos fatores de ordem ecológica, histórica, cultural, social e econômica e implicam em representações e imaginários sociais envolvendo escolhas e classificações ${ }^{[4]}$. É importante estabelecer uma distinção entre comida e alimento, onde a comida não é apenas uma substância alimentar, mas é, também, um modo, um estilo e um jeito de alimentar-se, que define não só aquilo que é ingerido, como também aquele que o ingere[5].

Reconhece-se a importância da alimentação e nutrição como área prioritária para as políticas saudáveis e o caráter intrinsecamente integral e de cidadania da segurança alimentar e nutricional, revelando a necessidade da avaliação qualitativa e quantitativa das políticas e programas de alimentação e nutrição. $\mathrm{O}$ tratamento dado ao papel do nutricionista e das ações nutricionais na atenção à saúde é destacável, como uma abordagem relevante para a Saúde Pública[ ${ }^{[2]}$.

A política de combate à fome teve o seu fortalecimento com a promulgação da Lei 11.346 de 15 de setembro de 2006, que cria o Sistema Nacional de Segurança Alimentar e Nutricional - SISAN visando assegurar o direito humano à alimentação adequada. $\mathrm{O}$ artigo 3o da Lei registra a definição de segurança alimentar e nutricional.

\footnotetext{
"A segurança alimentar e nutricional consiste na realização do direito de todos ao acesso regular e permanente a alimentos de qualidade, em quantidade suficiente, sem comprometer o acesso a outras necessidades essenciais, tendo como base práticas alimentares promotoras de saúde que respeitem a diversidade cultural e que sejam ambiental, cultural, econômica e socialmente sustentáveis"'[6].
}

O Programa de Aquisição de Alimentos PAA, instituído pelo artigo 19 da Lei no 10.696, de 2 de julho de 2003 e regulamentado pelo Decreto ㄲo7.775, de 4 de julho de 2012, integra o SISAN e tem como finalidades principais a promoção do acesso à alimentação e o incentivo para a agricultura familiar[7].

No grupo de entidades cadastradas e atendidas pelo Programa estão as Instituições sem fins lucrativos; ou privadas de caráter beneficente e/ou de caridade, que tenham por objetivo promover ações educativas para a sociedade. Essas Instituições, adquirem seus recursos econômicos, financeiros e materiais a partir de contribuições, doações e subvenções ${ }^{[8]}$.

As ações voltadas para a segurança alimentar e nutricional integram as novas demandas de saúde pública que favorecem a melhoria da qualidade de vida, contribuindo para a diminuição e controle do alto índice de obesidade e suas comorbidades. Diante do exposto, este estudo tem como objetivo avaliar a influência das ações educativas para a segurança alimentar nas cozinhas e a diminuição do desperdício de alimentos por meio do aproveitamento integral e métodos de conservação. 


\section{MATERIAL E MÉTODOS}

O estudo exploratório de análise descritiva envolveu seis Instituições atendidas pelo PAA na cidade de Araçatuba (São Paulo), com critérios beneficentes, que possuíam cozinha e desenvolviam algum tipo de serviço de alimentação no local.

A população alvo desse estudo foram funcionários e voluntários das Instituições que atendem 1317 pessoas, entre crianças, adultos e idosos.

O estudo foi desenvolvido em três fases:

1. Avaliação Inicial: realizada por meio da observação do local, onde foram pontuados quatro quesitos com valor máximo de 1 ponto e suas subdivisões com valores que variam entre 0 e 0,25 , sendo que 0 (zero) representava "inadequado as normas vigentes" e 0,25 (vinte e cinco centésimos) "adequado as normas vigentes" (ANVISA) ${ }^{[?]}$.

2. Intervenção Educativa: implementação de práticas educativas em três das Instituições. Os encontros aconteceram em cada uma das três Instituições e foram realizadas aulas práticas e dinâmicas, abordando temas relacionados à segurança alimentar e aproveitamento integral de alimentos. As outras três Instituições do grupo observação permaneceram sem intervenções.

3. Avaliação Final: reavaliação das três Instituições que receberam intervenções educativas.

Para a divisão dos grupos foi realizado um sorteio com envelopes lacrados, e separados dois grupos de três Instituições, sendo que um foi denominado grupo observação (numerado de 1 a 3), e outro denominado grupo intervenção (numerado de 4 a 6). As três Instituições do grupo intervenção receberam ações educativas e foram reavaliadas no final para análise da eficácia dessas ações.

As avaliações tiveram como direcionador um roteiro de avaliação técnica (APÊNDICES I e II) contendo quatro quesitos que foram subdivididos em subitens, sendo o primeiro o de higiene, que abordou higiene pessoal e saúde do trabalhador, higienização das mãos, riscos para contaminação cruzada, higiene de equipamentos e ambiental.
O segundo item de avaliação foi a recepção de alimentos, observou-se as características e quantidades dos alimentos recebidos, o armazenamento, controle de temperatura e transporte/entregador. No terceiro (técnicas de preparo), foi avaliada a higienização dos alimentos, a qualidade da água para uso na cozinha, os procedimentos para a conservação e controle de temperatura dos alimentos e o uso de óleo na cozinha, seu aquecimento, reutilização e descarte.

No último subitem, uso do aproveitamento integral de alimentos, avaliou a reutilização de sobras limpas, o uso de cascas, talos e sementes como integrantes das preparações, aplicação de técnicas de conservação e utilização de resíduos oriundos de aparas de alimentos, ou aproveitamento de partes não convencionais para preparo de outras receitas utilizando as cascas, talos e sementes para novas preparações.

Os critérios de inclusão da Instituição no referido estudo foram, a saber: possuir caráter beneficente, estarem vinculadas ao programa PAA, possuir cozinha (com algum tipo de serviço de alimentação no local) e possuir funcionários ou voluntários com atuação no setor de cozinha. Já os critérios para a exclusão da Instituição foram recusa e não concordância em assinar $\mathrm{o}$ Termo de Consentimento Livre Esclarecido ou não possuir funcionários e voluntários para treinamento.

A presente pesquisa está em consonância com a Resolução no 466, de 12 de dezembro de 2012 do Ministério da Saúde -MS[10]. Foi aprovado pelo Comitê de Ética em Pesquisa do Centro Universitário Católico Salesiano Auxilium - UniSALESIANO, sob o número do CAAE: 44427115.2.0000.5379, em 2015.

\section{RESULTADOS E DISCUSSÃO}

As Tabelas 1 e 2 permitem uma visão sobre as características desses locais quanto a sua adequação e inadequação às normas vigentes - CVS 5 para estabelecimentos e serviços de alimentação, antes e após as ações educativas. Demonstra ainda, no quarto quesito, a utilização ou não de aproveitamento integral e alimentos nas unidades. 
A Tabela 1 representa a pontuação atribuída as Instituições antes da aplicação das ações educativas. Foram analisados os dados das Instituições do "grupo observação", classificadas de 1 a 3 e do "grupo intervenção educativa", classificados com numeração de 4 a 6. Apresenta ainda as Instituições que possuíam ou não um nutricionista responsável - RT, constatando-se que em quatro dos seis locais estudados apenas dois (Instituições 5 e 6) não possuíam o RT.

Ao final da Tabela 1 foram inseridos os resultados totais das pontuações obtidas nos quatro quesitos avaliados, elucidando que o valor máximo alcançado para cada um desses itens somava 1 ponto e os valores totais finais poderiam atingir 4 pontos.

Esse padrão norteou a análise do desempenho, interpretando que quanto mais próximo da pontuação 4 melhor adequação as exigências sanitárias e maior conhecimento e aplicação de aproveitamento integral de alimentos.

Tabela 1. Pontuação inicial (antes) das intervenções educativas em instituições beneficentes. Araçatuba, 2015

\begin{tabular}{|c|c|c|c|c|c|c|}
\hline \multirow{4}{*}{ Instituição } & \multicolumn{3}{|c|}{ Grupo: Observação } & \multicolumn{3}{|c|}{ Grupo: Intervenção Educativa } \\
\hline & 1 & 2 & 3 & 4 & 5 & 6 \\
\hline & \multicolumn{4}{|c|}{ Gestão por Nutricionista - RT } & \multicolumn{2}{|c|}{ Não possuíam RT } \\
\hline & Pontuação & Pontuação & Pontuação & Pontuação & Pontuação & Pontuação \\
\hline \multicolumn{7}{|l|}{ Quesito 1: Higiene } \\
\hline 1.1 - Higiene pessoal e saúde do trabalho & 0,25 & 0,25 & 0,25 & 0,25 & 0,00 & 0,00 \\
\hline 1.2 - Higienização das mãos & 0,25 & 0,25 & 0,25 & 0,25 & 0,00 & 0,00 \\
\hline 1.3 - Riscos para contaminação cruzada & 0,00 & 0,00 & 0,00 & 0,00 & 0,00 & 0,00 \\
\hline 1.4 - Higiene equipamento e ambiental & 0,25 & 0,00 & 0,00 & 0,25 & 0,00 & 0,00 \\
\hline \multicolumn{7}{|l|}{ Quesito 2: Recepção de alimentos } \\
\hline $\begin{array}{l}2.1 \text { - Características e quantidades dos alimentos } \\
\text { recebidos }\end{array}$ & 0,25 & 0,25 & 0,25 & 0,25 & 0,00 & 0,00 \\
\hline 2.2 - Armazenamento & 0,25 & 0,25 & 0,25 & 0,00 & 0,00 & 0,00 \\
\hline 2.3 - Controle de temperatura & 0,00 & 0,00 & 0,00 & 0,00 & 0,00 & 0,00 \\
\hline 2.4 - Transporte/Entregador & 0,00 & 0,00 & 0,00 & 0,00 & 0,00 & 0,00 \\
\hline \multicolumn{7}{|l|}{ Quesito 3: Técnica de preparo } \\
\hline 3.1 - Higienização dos alimentos & 0,00 & 0,00 & 0,25 & 0,25 & 0,00 & 0,00 \\
\hline 3.2 - Qualidade da água & 0,25 & 0,25 & 0,25 & 0,25 & 0,25 & 0,25 \\
\hline $\begin{array}{l}3.3 \text { - Conservação e controle da temperatura dos } \\
\text { alimentos }\end{array}$ & 0,00 & 0,00 & 0,00 & 0,00 & 0,00 & 0,00 \\
\hline 3.4 - Óleo: aquecimento, reutilização e descarte & 0,25 & 0,25 & 0,25 & 0,25 & 0,25 & 0,25 \\
\hline \multicolumn{7}{|l|}{ Quesito 4: Aproveitamento integral de alimentos } \\
\hline 4.1 - Reutilização de sobras limpas & 0,25 & 0,00 & 0,25 & 0,25 & 0,25 & 0,25 \\
\hline $\begin{array}{l}4.2 \text { - Uso de cascas, talos e sementes nas } \\
\text { preparações }\end{array}$ & 0,00 & 0,00 & 0,00 & 0,25 & 0,00 & 0,25 \\
\hline 4.3 - Técnicas de conservação & 0,00 & 0,00 & 0,00 & 0,25 & 0,25 & 0,00 \\
\hline 4.4 - Resíduos oriundos de aparas de alimentos & 0,00 & 0,00 & 0,00 & 0,00 & 0,00 & 0,00 \\
\hline Total & 2,00 & 1,50 & 2,00 & 2,50 & 1,00 & 1,00 \\
\hline
\end{tabular}


Os resultados demonstram as dificuldades encontradas em todas as seis Instituições estudadas, tais como, os riscos de contaminação cruzada no seu fluxo de operações (Quesito 1, item 1.3), conferência e controle da temperatura dos alimentos no momento da entrega (Quesito 2, item 2.3), adequação quanto ao transporte/entregador (Quesito 2, item 2.4) e a conservação e controle de temperatura dos alimentos na área de produção e distribuição (Quesito 3, item 3.3). Cabe lembrar que:

"Em todas as etapas do processo produtivo, as instalações devem ser separadas por meios físicos ou por outras medidas efetivas, de forma a facilitar os procedimentos de higienização e manutenção, por meio de fluxos contínuos, sem cruzamento de etapas e linhas do processo produtivo. O retorno de utensilios sujos não deve oferecer risco de contaminação aos utensílios limpos [...]. Se a área física não permitir esta separação, todas as operações de pré-preparo devem ser realizadas inicialmente, seguidas da higienização dos equipamentos, utensilios, recipientes, bancadas, superfícies, pias, piso e qualquer local contaminado. As operações do preparo final dos alimentos devem se realizar em horário diferente do prépreparo num ambiente higienizado"[?].

Nenhuma das instituições possuía termômetros para coleta de temperatura dos alimentos, com exceção daqueles que dispunham de câmaras frias com termômetros acoplados aos equipamentos.

Diferentes tipos de microrganismos podem desenvolver-se nos produtos alimentícios, seja por fatores intrínsecos ou extrínsecos que afetam o crescimento microbiano e entre estes, a temperatura é o fator mais importante, pois a manutenção da mesma abaixo de valores recomendados constitui uma barreira ao crescimento microbiano de modo geral. No entanto, se as temperaturas não forem mantidas, notadamente no transporte dos produtos alimentares, podem ser geradas condições favoráveis ao desenvolvimento microbiano que podem promover a ocorrência de situações com implicações graves para o consumidor final[11].

No ato do recebimento de matérias primas, ingredientes, alimentos industrializados ou prontos para consumo, as temperaturas dos produtos que necessitam de condições especiais de conservação devem ser conferidas e registradas em planilhas próprias e recusados caso estejam em desacordo com as temperaturas orientadas pela legislação CVS-5 ou indicada no rótulo pelo fabricante ${ }^{[9]}$.

Quanto aos cuidados com os alimentos prontos, não foram encontrados nenhum tipo de controle para garantir a segurança dos alimentos em temperaturas recomendadas, utilizando-se do binômio tempo x temperatura, no período de espera, ou seja, do momento em que o alimento ficou pronto até o final do serviço de distribuição. Esses alimentos permaneciam no interior das cozinhas, porcionados ou não em cubas de distribuição, porém sem o uso de equipamento ou técnica, por exemplo, o banho-maria, para assegurar a manutenção da temperatura até último horário do serviço.

As normas vigentes para estabelecimentos ou serviços de alimentação dispõem sobre as temperaturas adequadas para manter os alimentos seguros para o consumo, sejam preparações frias ou quentes. O tempo de exposição dos alimentos sem o acompanhamento e controle do tempo relacionado a temperatura desses alimentos podem acarretar no comprometimento dessas preparações com a proliferação de microrganismos patogênicos ${ }^{[9]}$.

Durante a avaliação do uso de resíduos de aparas de alimentos (Quesito 4, item 4.4) não foram identificados em nenhuma das Instituições procedimentos para a utilização desse tipo de recurso para elaboração de preparações culinárias.

A reutilização de alimentos é permitida desde que tenham sido manipulados com observância das Boas Práticas, contudo a reutilização não inclui os restos dos pratos dos consumidores $[9]$.

Para aproveitar melhor os alimentos e evitar o desperdício é preciso escolher bem, preferindo alimentos da época, conservar em locais limpos, em temperaturas adequadas para cada tipo de alimento e prepara-los de forma segura, lavar bem, não retirar cascas grossas e preparar apenas a quantidade necessária para a refeição. As sobras e aparas, desde que mantidas em condições seguras podem tornar-se parte principal de inúmeras preparações como bolinhos, croquetes, sucos, doces, bolos, refogados, sopas, geleias, suflês, tortas entre outras. 
A Tabela 2 demonstra a pontuação atribuída as Instituições após a aplicação das ações educativas. Essas pontuações conduzem o estudo para a análise final dos resultados, onde se observou evolução ou não do comportamento dos locais em relação aos quesitos abordados nas intervenções.

Tabela 2. Pontuação (final) após intervenções educativas em instituições beneficentes. Araçatuba, 2015

\begin{tabular}{|c|c|c|c|c|c|c|}
\hline \multirow{4}{*}{ Instituição } & \multicolumn{3}{|c|}{ Grupo: Observação } & \multicolumn{3}{|c|}{ Grupo: Intervenção Educativa } \\
\hline & 1 & 2 & 3 & 4 & 5 & 6 \\
\hline & \multicolumn{4}{|c|}{ Gestão por Nutricionista - RT } & \multicolumn{2}{|c|}{ Não possuíam RT } \\
\hline & Pontuação & Pontuação & Pontuação & Pontuação & Pontuação & Pontuação \\
\hline \multicolumn{7}{|l|}{ Quesito 1: Higiene } \\
\hline 1.1 - Higiene pessoal e saúde do trabalho & 0,25 & 0,25 & 0,25 & 0,25 & 0,00 & 0,00 \\
\hline 1.2 - Higienização das mãos & 0,25 & 0,25 & 0,25 & 0,25 & 0,00 & 0,00 \\
\hline 1.3 - Riscos para contaminação cruzada & 0,00 & 0,00 & 0,00 & 0,00 & 0,00 & 0,00 \\
\hline 1.4 - Higiene equipamento e ambiental & 0,25 & 0,00 & 0,00 & 0,25 & 0,25 & 0,00 \\
\hline \multicolumn{7}{|l|}{ Quesito 2: Recepção de alimentos } \\
\hline $\begin{array}{l}2.1 \text { - Características e quantidades dos alimentos } \\
\text { recebidos }\end{array}$ & 0,25 & 0,25 & 0,25 & 0,25 & 0,00 & 0,00 \\
\hline 2.2 - Armazenamento & 0,25 & 0,25 & 0,25 & 0,00 & 0,00 & 0,00 \\
\hline 2.3 - Controle de temperatura & 0,00 & 0,00 & 0,00 & 0,00 & 0,00 & 0,00 \\
\hline 2.4 - Transporte/Entregador & 0,00 & 0,00 & 0,00 & 0,00 & 0,00 & 0,00 \\
\hline \multicolumn{7}{|l|}{ Quesito 3: Técnica de preparo } \\
\hline 3.1 - Higienização dos alimentos & 0,00 & 0,00 & 0,25 & 0,25 & 0,25 & 0,00 \\
\hline 3.2 - Qualidade da água & 0,25 & 0,25 & 0,25 & 0,25 & 0,25 & 0,25 \\
\hline $\begin{array}{l}3.3 \text { - Conservação e controle da temperatura dos } \\
\text { alimentos }\end{array}$ & 0,00 & 0,00 & 0,00 & 0,00 & 0,00 & 0,00 \\
\hline 3.4 - Óleo: aquecimento, reutilização e descarte & 0,25 & 0,25 & 0,25 & 0,25 & 0,25 & 0,25 \\
\hline \multicolumn{7}{|l|}{ Quesito 4: Aproveitamento integral de alimentos } \\
\hline 4.1 - Reutilização de sobras limpas & 0,25 & 0,00 & 0,25 & 0,25 & 0,25 & 0,25 \\
\hline $\begin{array}{l}4.2 \text { - Uso de cascas, talos e sementes nas } \\
\text { preparações }\end{array}$ & 0,00 & 0,00 & 0,00 & 0,25 & 0,25 & 0,25 \\
\hline 4.3 - Técnicas de conservação & 0,00 & 0,00 & 0,00 & 0,25 & 0,25 & 0,00 \\
\hline 4.4 - Resíduos oriundos de aparas de alimentos & 0,00 & 0,00 & 0,00 & 0,00 & 0,00 & 0,00 \\
\hline Total & 2,00 & 1,50 & 2,00 & 2,50 & 1,75 & 1,00 \\
\hline
\end{tabular}

Os dados reunidos na Tabela 2 demonstram que houve o crescimento na pontuação da Instituição número 5 após intervenções educativas. Esse aumento decorreu do fato do local dispor de melhor estrutura física e de pessoal quando comparado com a Instituição número 6, favorecendo com isso que novos conhecimentos fossem incluídos na rotina diária, fato importante no aumento da disponibilidade e motivação das funcionárias que passaram a adotar esses procedimentos de forma produtiva.

A capacitação dos manipuladores de alimentos (Quesito 1, item 1.4) por meio de treinamentos significa contribuir não apenas para a melhoria da qualidade higiênico-sanitária, mas para o aperfeiçoamento das técnicas e processamento utilizados, sendo esta uma forma de transmitir conhecimentos e que deve acontecer periodicamente e com acompanhamento para avaliação da mudança de atitude e aquisição dos novos conhecimentos ${ }^{[12]}$.

Examinando os dos dados relativos às instituições 5 e 6 verifica-se que esses locais não contavam com a atuação do RT, apresentavam estruturas semelhantes e possuíam necessidades estruturais também parecidas, como a falta de produtos recomendados pela ANVISA para uso na cozinha, falta de equipamentos, dificuldade de realização das atividades de rotina no que tange a higienização de equipamentos e ambiental, falha na elaboração dos cardápios e pouco ou nenhum método para conservação ou aproveitamento integral dos alimentos. 
$\mathrm{Na}$ avaliação dos procedimentos utilizados para higienização dos hortifrútis (Quesito 3, item 3.1) observou-se dificuldades quanto a operação e aos produtos normatizados para este fim. Apenas duas das seis instituições adotavam esse procedimento na avaliação inicial e, posteriormente a ação educativa, demonstração da operação e esclarecimentos quanto aos produtos autorizados pela ANVISA, uma das três instituições capacitadas, a de número 5 , incorporou esse procedimento à sua rotina diária.

Os alimentos hortifrutícolas devem ser higienizados em local apropriado, com água potável e produtos desinfetantes para uso em alimentos, regularizados pela ANVISA e deve atender as instruções recomendadas pelo fabricante. A higienização compreende a remoção mecânica de partes deterioradas e de sujidade, sob água corrente potável, seguida de desinfecção por imersão em solução desinfetante, por quinze a trinta minutos, seguidos de enxague final com água potável[9].

Existem aproximadamente 250 tipos de doenças alimentares que são responsáveis por sérios problemas de saúde pública, quadros resultantes da ingestão de alimentos contaminados por esses microrganismos, conhecidos como Doenças Transmitidas por Alimentos (DTA) ${ }^{[13]}$.

Dados do Sistema de Vigilância em Saúde registraram de 1999 a 2008, 6.062 surtos de DTA que acometeram 117.330 pessoas e ocasionaram 64 óbitos. As regiões Sul e Sudeste notificaram $83 \%$ dos surtos. Foi verificado que a Salmonella spp. foi responsável por 1.275 surtos (42\%), seguida pelo S. aureus responsável por 600 surtos $(20 \%)$. O microrganismo B. cereus foi o terceiro principal agente, sendo responsável por 205 surtos $(7 \%)^{[14]}$.

No que se refere ao quesito aproveitamento integral dos alimentos (Quesito 4, item 4.2) os resultados foram modestos. Percebeu-se que existe um forte tabu sobre a utilização de alimentos com cascas e/ou uso das partes não convencionais para preparações. Para desmistificar o tabu, foram apresentados doces e patês com cascas para degustação, além disso, material de apoio com dicas e receitas para incentivar o pessoal que atua nas cozinhas para que façam experimentações com esses produtos. Com essa dinâmica o efeito foi positivo, causando reação de surpresa no momento da degustação.
A partir do momento em que as pessoas são capacitadas para atuação em curto, médio ou longo prazo, percebe-se facilmente que as mesmas se sentem parte de um mundo de informações, de novos horizontes e desafios. À medida que as pessoas se sentem seguras quando dominam a atividade que exercem, melhores serão os resultados, aprimorando o ambiente de trabalho, reduzindo-se o desperdício de tempo e o trabalho, gerando motivação que reflete em desempenho, não pela obrigação do contrato de trabalho e sim como conduta ${ }^{[15]}$.

No presente estudo, observa-se que duas Instituições possuíam RT, sendo ambas pertencentes ao grupo observação, contudo esse não foi um fator limitante do estudo, já que o sorteio para a composição dos grupos foi realizado aleatoriamente. Também o cadastro das instituições no programa não registra exigência de um nutricionista responsável que atue no local, entretanto é preciso considerar que a presença de um RT nessas instituições atribuiu-lhes melhores resultados.

A presença do RT nos locais mostrou ser um fator diferencial para que a organização do trabalho, as aplicações de procedimentos e técnicas alinhadas com a legislação favorecessem uma melhor produtividade. Estruturalmente, essas instituições também apresentaram maior gama de produtos em conformidade com a legislação para a utilização na cozinha e melhor aproveitamento dos alimentos recebidos.

Estudo realizado na cidade de Goiânia - GO sobre o controle de tempo e temperatura na produção de refeições, envolvendo três restaurantes, constatou que apenas um possuía RT. Os resultados demonstraram que nos dois estabelecimentos que não possuíam nutricionista não havia monitoramento do tempo e de temperaturas e nenhum outro tipo de controle, enquanto que no terceiro restaurante, com RT, foram observados além dos controles de tempo e temperatura, a coleta de amostras, etiquetas de identificação e uso adequado da solução clorada para desinfecção. Os achados confirmam a importância do profissional para garantir uma alimentação de boa qualidade sanitária ${ }^{[16]}$.

A cada ano, um terço dos alimentos produzidos no mundo vai para no lixo, isso significa que $30 \%$ das terras agrícolas disponíveis são usadas para 
produzir alimentos que nunca serão consumidos. Esses são desperdícios e perdas que acontecem no decorrer de toda cadeia produtiva, acarretando em sérias consequências ambientais. Com base nisso, o desperdício de alimentos torna-se uma questão cultural, equivocada pela ideia de alta produtividade e de que não haverá falta. Com isso não há economia, consome-se apenas a polpa do alimento e inutilizam-se cascas, folhas e talos sem nem mesmo experimentar a sua aplicação nas preparações ${ }^{[17,18]}$.

A educação alimentar é fundamental para vencer o desperdício, o que não se resume em ensinar o indivíduo a alimentar-se bem, mas também a dar esse sentido coletivo ao alimento, informando que o alimento é um direito de todos, previsto em Constituição[19].

Aproveitar tudo o que o alimento pode oferecer como fonte de nutrientes é uma prática da cozinha sustentável de responsabilidade compartilhada que afeta a vida de milhões de pessoas no mundo que vivem em situação de fome e insegurança alimentar [18].

A organização da sociedade é condição essencial para formular e executar políticas de segurança alimentar e nutricional. Segundo dados da Prefeitura Municipal de Araçatuba, por meio da Secretaria Municipal de desenvolvimento Agroindustrial, órgão responsável pela implantação do PAA na cidade, no período de janeiro a dezembro de 2014, foram atendidas 49 Instituições sociais, que por sua vez, assistem mensalmente 5.438 adultos, 5.242 crianças e 1.505 idosos, totalizando 12.367 pessoas que receberam algum tipo de complementação por meio das doações realizadas pelo programa. Esses números geraram uma média de $71.693 \mathrm{~kg}$ de alimentos mensalmente e um total de $860.316 \mathrm{~kg}$ de alimentos doados no ano, perfazendo um per capita de aproximadamente $6 \mathrm{~kg}$ de alimentos por pessoa, por mês ${ }^{[20]}$.

De acordo com os registros disponibilizados pelo setor de controle do programa, existe uma variabilidade nas culturas produzidas, que proporcionam uma importante variedade de nutrientes ofertados, como no grupo das frutas, legumes, verduras e em menor proporção a produção de feijão comum, o leite de vaca integral tipo $\mathrm{C}$, a bebida láctea, iogurte e ovos de galinha de granja[20].
Considerando a variedade da produção e a sazonalidade para as diferentes culturas, visto que são alimentos que complementam as refeições e mudam a situação alimentar das pessoas atendidas pelo programa (por meio da oferta de nutrientes), torna-se necessário desenvolver métodos e mecanismos de conservação para ampliar o aproveitamento dos nutrientes e dos próprios alimentos e sua oferta fora do período de safra.

O não reaproveitamento dos alimentos decorre da falta de informações, falta de hábito, costumes, receio ou até mesmo por falta de acesso ou condições apropriadas para adquirir e preparar ${ }^{[19]}$.

As estratégias de saúde pública são em geral voltadas para toda a população e há vários cenários identificados como espaços favoráveis à promoção de recomendações de estilo de vida saudável: a família, e/ou domicílio, a escola, o ambiente de trabalho, serviços de saúde, bairros e comunidades ${ }^{[21]}$.

É importante o incentivo às práticas de alimentação, principalmente com a colaboração do nutricionista, profissional da saúde que estuda as funções e os efeitos dos alimentos no organismo para melhorar a qualidade de vida e prevenir doenças relacionadas à má alimentação[19].

A educação alimentar e nutricional propicia conhecimentos e habilidades que permitem às pessoas produzirem, descobrirem, selecionarem e consumirem alimentos de forma adequada, saudável e segura, assim como, as estimula para que se tornem conscientes quanto as práticas alimentares saudáveis, fortalecendo as culturas alimentares das diversas regiões do país e diminuindo o desperdício por meio do aproveitamento integral dos alimentos ${ }^{[22]}$.

\section{CONCLUSÃO}

A partir da análise dos resultados obtidos verificou-se que as ações educativas são ferramentas efetivas para transmitir conhecimentos. A implantação de treinamentos constantes para a capacitação dos funcionários e voluntários que atuam nas cozinhas das Instituições deve acontecer de forma planejada e sistemática para estimular a conscientização desses colaboradores e ampliar as técnicas de preparo e conservação dos alimentos. 
Utilizar procedimentos adequados para manipular os alimentos, produzindo refeições microbiologicamente seguras e aumentando a biodisponibilidade de nutrientes nas preparações, contribuem para a ingestão adequada de elementos essenciais ao bom funcionamento do corpo humano, que consiste numa forma de prevenir doenças ocasionadas tanto pela escassez quanto pelo excesso de alimentos não nutritivos.

O envolvimento dos funcionários requer motivação intrínseca, contudo o acompanhamento do nutricionista estimulando conhecimentos e práticas valorizam a equipe e tem influência no comportamento e adesão de novos conceitos que irão impactar na qualidade da produtividade.

\section{REFERÊNCIAS}

[1] Monteiro CA, Mondini L, Costa RBL. Mudanças na composição e adequação nutricional da dieta familiar nas áreas metropolitanas do Brasil (1988-1996). Rev. Saúde Pública [Internet]. 2000 [acesso em 2015 ago 10]; 34(3):251-8. Disponível em: http://www.scielo.br/scielo

[2] Taddei JAAC, Lang RMF, Silva GL, Toloni MHA. Nutrição em Saúde Pública. Rev Bras Saúde Matern Infant Recife [Internet]. 2013 [acesso em 2015 jul 20]; 13(3):167-8. Disponível em: http://www.scielo.br/scielo

[3] Tardido AP. O impacto da modernização na transição nutricional e obesidade. Rev Bras Nutr Clin. [Internet]. 2006 [acesso em 2014 out 10]; 21(2):117-24. Disponível em: http://www.scielo.br/scielo

[4] Maciel ME. Identidade Cultural e Alimentação. In: Canesqui AM \& Garcia RW. Antropologia e nutrição: um diálogo possível. Rio de Janeiro: Fiocruz, 2005. p. 49-55.

[5] Damatta R. O que faz o brasil, Brasil? [Internet]. 1986 [acesso em 2015 set. 12]. Disponível em: http://www.hugoribeiro.com.br/biblioteca-digital/Da_Matta-

O_que_faz_Brasil_Brasil.pdf

[6] Brasil. Lei no 11.346, de 15 de setembro de 2006. Sistema Nacional de Segurança Alimentar e Nutricional - SISAN. Diário Oficial da União. 2006 set. 18.

[7] Brasil. Decreto no 7.775, de 04 de julho de 2012. Institui o Programa de Aquisição de Alimentos. Diário Oficial da União. 2012 jul. 05, Sessão 1:3.

[8] Guse JC, Freitas SL. A Gestão e controle contábil para instituições sem fins lucrativos: um estudo de caso [Internet]. 2010 [acesso em 2015 set 12]. Disponível em: http://www.sober.org.br/palestra/15/1243.pdf
[9] Brasil. Portaria CVS 5, de 9 de abril de 2013. Aprova o regulamento técnico sobre Boas Práticas para Estabelecimentos Comerciais de Alimentos e para Serviços de Alimentação. Diário Oficial da União. 2013 abr. 19, Seção 1:32-5.

[10] Brasil. Conselho Nacional de Saúde, Comissão Nacional de Ética em Pesquisa. Resolução no 466, de 12 de dezembro de 2012. Institui diretrizes e normas regulamentadoras de pesquisa envolvendo seres humanos. Diário Oficial da União. 2013 jun. 13. Seção 1:112.

[11] Baptista P, Pinheiro G, Alves P. Sistema de Gestão em Segurança Alimentar. Forvisão Consultoria em Formação Integrada [Internet]. 2003 [citado em 2015 nov 02]. Disponível em: http://docbweb.act.gov.pt/docbwebb/psqsimp.asp

[12] Saccol ALF, Rubim BA, Mesquita MO, Welter L. Importância de treinamentos de manipuladores em boas práticas. Disc. Scientia. Série: Ciências da Saúde [Internet]. 2006 [acesso em 2015 out 10]; 7(1):91-9. Disponível em: http://sites.unifra.br

[13] Silva Júnior EA. Manual de Controle Higiênico Sanitário em Serviços de Alimentação. 6.ed. São Paulo: Varela; 2008.

[14] Secretaria de Vigilância em Saúde - SVS. Vigilância Epidemiológica de Doenças Transmitidas por alimentos no Brasil [Internet]. Brasília (DF): 2015. [acesso em 2015 nov 10]. Disponível em: http://www.saude.gov.br/svs

[15] Araújo LCG, Garcia AA. Gestão de pessoas: estratégias e integração organizacional. 2.ed. São Paulo: Atlas; 2009.

[16] Carvalho A, Ricardo F, Moraes M. Controle de tempo e temperatura na produção de refeições de restaurantes comerciais na cidade de Goiânia - GO. Demetra [Internet]. 2012 [acesso em 2015 nov 10]; 7(2):85-96. Disponível em: http://www.epublicacoes.uerj.br

[17] Teixeira AR. Lugar de comida não é na lixeira. Revista e Publicação Sesc. 2015;22(4).

[18] Menezes F. Lugar de comida não é na lixeira. Revista e Publicação Sesc. 2015;22(4).

[19] Rosa TCM, Cardoso GM, Schimitez LC. Aproveitamento Integral dos Alimentos: uma questão sociocultural. In: Anais da Mostra de Trabalhos em Saúde Pública no 3 [Internet]; 2009; Paraná. Universidade do Oeste Paulista [acesso em 2015 out. 12]. Disponível em: http://cac-php.unioeste.br/eventos/saudepublica

[20] Secretaria Municipal de Desenvolvimento Agroindustrial. Araçatuba: Programa de Aquisição de Alimentos; 2015.

[21] Mullis RM, Blair SN, Aronne LJ, Bier DM, Denke M.A, et al. Prevention Conference VII: Obesity, a worldwide epidemic related to heart disease and stroke: Group IV: prevention/treatment. Circulation [Internet]. 2004 [acesso em 2015 mar 18]; 110(18):484488. Disponível em: http://circ.ahajournals.org 
Segurança Alimentar nas Instituições Beneficentes. Aro et al.

[22] Prado SD, Gugelmin SA, Mattos RA, Silva JK, Olivares PSG. A pesquisa sobre segurança alimentar e nutricional no Brasil de 2000 a 2005: tendências e desafios. Ciênc. Saúde Coletiva [Internet]. 2009 [acesso em 2015 out. 12]; 15(1):7-18. Disponível em: http://www.scielo.br 


\section{Apêndice I - Roteiro de Avaliação Técnica}

APÉNDICE I

Projeto: Segurança Alimentar na Saúde da População atendida pelas Ins tituições Beneficentes cadas tradas no Programa de Aquisição de Alimentos na cidade de Araçatuba-SP

ROTEIRO DE AVALIAÇÃ̃ TÉCNICA.

Gestão da Segurança Alimentar

Razẫo Social:

Data:

Endereço:

N ${ }^{\circ}$ Funcionários/Voluntários
CNPJ $n^{\circ}$ $N^{\circ}$ Pessoas Atendidas

Quesito 1: Higiene

ITEM

1.1 Higiene Pessoal e saúde do trabalhador

1.2 Higienização das mãos

1.3 Riscos para Contaminação Cruzada

1.4 Higiene Equipamentos e Ambiental

Tota1

Quesito 2: Recepção de Alimentos

2.1 Caractéristicas e quantidades dos alimentos recebidos Armazenamento

Controle de Temperatura

Transporte/Entregador

Quesito 3: Técnicas de Preparo

\begin{tabular}{l|l|l}
\hline ITEM & REQUISITO & PONTUACÃ
\end{tabular}

3.2 Qualidade da higua

3.3 Conservaçao e controle de lemperatura dos

3.4 Óleo: Aquecimento, Reutilização e Descarte

PONTUAÇÃO

Quesito 4: Aproveitamento Integral de Alimentos

ITEM

4.1 Reutilização de sobras limpas

4.2 Uso de cascas, talos e sementes nas preparações

4.3 Técnicas de Conservação

4.4 Residuos oriundos de aparas de alimentos

observação: Total de pontos por quesito $=1,0$

pontua ça $0=$ inadequado

$0,25=$ adequado 


\section{Apêndice II - Roteiro de Avaliação Técnica - Avaliação}

\begin{tabular}{|c|c|c|}
\hline Proje & 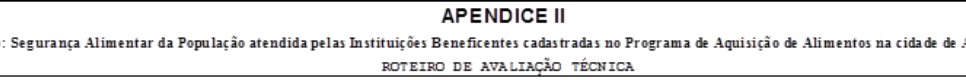 & açatuba-SP \\
\hline Queai & to 1: Higiene & \\
\hline ITEM & REQUISITO & PONTUAÇÃo \\
\hline 1.1 & 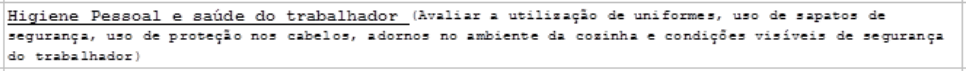 & \\
\hline 1.2 & 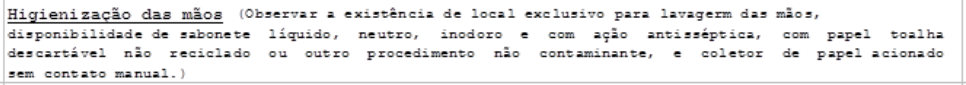 & \\
\hline 1.3 & 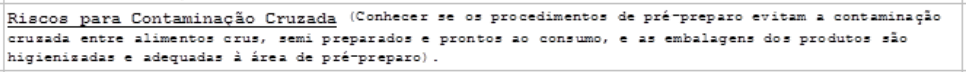 & \\
\hline 1.4 & 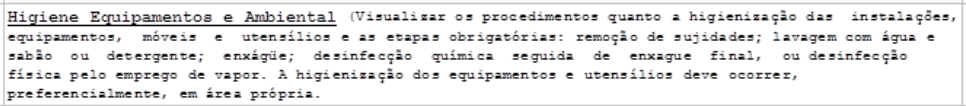 & \\
\hline & Totz1 & 0 \\
\hline Quesit & to 2: Recepção de Alimentos & \\
\hline ITEM & REQUISI TO & PONTUAÇÃ \\
\hline 2.1 & 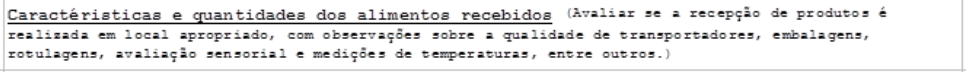 & \\
\hline 2.2 & 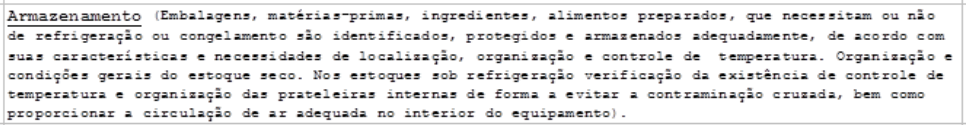 & \\
\hline 2.3 & 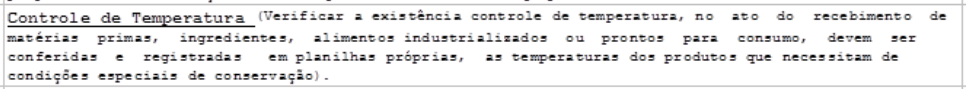 & \\
\hline 2.4 & $\begin{array}{l}\text { Transporte/Entregador (Veiculo exclusivo para trangporte de alimentos, com devida higenizaçâ. } \\
\text { Alimentos trangportados de maneira adequada e identificados, em condiços adequada de tempo e mperatura) }\end{array}$ & \\
\hline & Tota1 & 0 \\
\hline Quesit & to 3: Técnicas de Preparo & \\
\hline ITEM & REQUISITO & PONTUAÇÃO \\
\hline 3.1 & 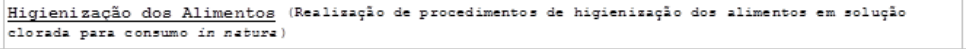 & \\
\hline 3.2 & 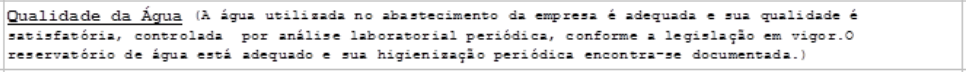 & \\
\hline 3.3 & 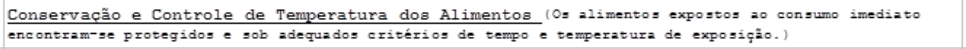 & \\
\hline 3.4 & 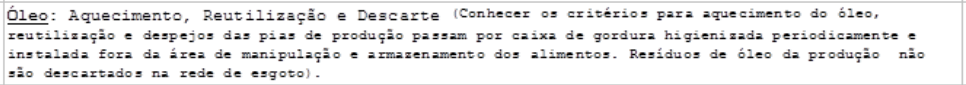 & \\
\hline & Total & 0 \\
\hline Quesit & to 4: Aproveitamento Integral de Alimentos & \\
\hline ITEM & REQUISI TO & PONTUAÇÃO \\
\hline 4.1 & $\begin{array}{l}\text { Reutilizacão de sobras limpas (Verificar a utilizaçấ das sobras limpas, a segurança na sua } \\
\text { conservaçấ em temperaturas adequadas e motivos de ocorrerem as sobrag) }\end{array}$ & \\
\hline 4.2 & $\begin{array}{l}\text { Uso de cascas, talos e sementes nas preparacões (Aproveitamento integral de alimentos, uso de } \\
\text { cascas a talos nas preparaços. Ex: uso da abóbora com casca, suco do abacaxi utilizando a casca, chuchu } \\
\text { com casca, refogar couve com talos, . . .) }\end{array}$ & \\
\hline 4.3 & 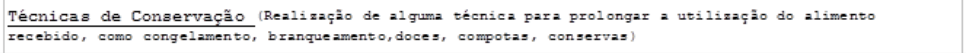 & \\
\hline 4.4 & $\begin{array}{l}\text { Resíduos oriundos de aparas de alimentos (Uso de "sobra", "apara" de alimentos para prepato de } \\
\text { outra receita. Ex: doce da casca de banana, melâo, casca da batatinha) }\end{array}$ & \\
\hline
\end{tabular}

